\title{
A description of interestrus and interservice intervals and associated fertility in 16 United Kingdom dairy herds
}

\author{
T. Greenham, ${ }^{1 *}$ G. Oikonomou, ${ }^{2}$ and D. H. Grove-White ${ }^{2}$ \\ ${ }^{1}$ Advance Milking Limited, The Cornhouse, Iscoyd, Whitchurch, Shropshire, SY13 3AU, United Kingdom \\ ${ }^{2}$ University of Liverpool, Leahurst Campus, Neston, Wirral, CH64 7TE, United Kingdom
}

\section{ABSTRACT}

Understanding the changes that have occurred in reproductive management and physiology of the dairy cow is necessary to reverse the trend of declining fertility. In this study we analyzed the intervals between estrus events, as detected using tail chalk, in a population of 6,092 dairy cows from 16 herds in the central United Kingdom. Intervals were categorized by absence or presence of an insemination at the first estrus event, being designated interestrus intervals and interservice intervals, respectively. Modal interestrus interval was $21 \mathrm{~d}$, as has been commonly described. Interservice interval was significantly longer than interestrus interval, with a modal value of $22 \mathrm{~d}$. Multivariable analysis identified explanatory variables for intervals between estrus events, with random effects modeling accounting for clustering within herds and within individual cows. Intraclass correlation coefficients indicated that herd identity has a negligible effect, whereas animal identity accounts for $9 \%$ of interval variation. Parity, days in milk, insemination at the first estrus of the interval, and interval number within lactation all affected the interval. Logistic regression modeling indicated that interval length is also associated with the outcome of pregnancy. These findings indicate that intervals following an insemination are both longer than previously described and longer than interestrus intervals with no insemination event. The data also suggest that longer interservice interval length may be more conducive to subsequent conception than shorter intervals. Several factors appear to influence interestrus events and further work is required to investigate the underlying physiological mechanisms of these phenomena.

Key words: interestrus interval, interservice interval, estrous cycle, tail chalk

Received March 16, 2018.

Accepted September 11, 2018.

*Corresponding author: tom@advancemilking.com

\section{INTRODUCTION}

The estrous cycle is the regularly repeating period between estrus events. For over 4 decades the dairy cow's estrous cycle length has been described as having a mean of $21 \mathrm{~d}$ with a range of 18 to $24 \mathrm{~d}$ (Barr, 1975; Gwazdauskas et al., 1981). Interestrus interval is defined as the time period between consecutive estrus events. Interservice interval is a related parameter, being the time period between consecutive inseminations, which are associated with diagnosed estrus events. These figures still provide a point of reference for clinicians and researchers, as well as informing reproductive management software (Forde et al., 2011). However, with recent work demonstrating marked differences between the reproductive traits of the modern dairy cow and her genetically distant predecessors, it is plausible that these parameters may no longer accurately describe the dairy cow's estrous cycle (Royal et al., 2000; Lopez-Gatius, 2003; Pryce et al., 2004). Indeed, recent work has shown that interservice interval has a mode of $22 \mathrm{~d}$, with an upper range of $28 \mathrm{~d}$ (Remnant et al., 2015). However, this data set focused exclusively on interservice interval and did not examine intervals following estrus events with no insemination. As such this work was unable to determine whether the increased interval was present in all interestrus intervals, due to changes in estrus physiology, or was solely associated with intervals following insemination. Milk progesterone measurement has also been used to describe estrus cycle length, with one study demonstrating a median cycle length of 23 d (Blavy et al., 2018).

Any changes in the dairy cow's estrous cycle bring into question the suitability of the current measures used to assess fertility performance. Intervals between detected estrus events are used as markers of estrus detection accuracy, estrus detection efficiency, and as a proxy measure of late embryonic loss (Gaines, 1989). Two well-established measures of estrus detection performance are Wood's index of estrus detection efficiency and the Warren equation of estrus detection accuracy. Wood's index divides 21 by the mean inter- 
estrus interval for the herd and multiplies by 100, with a target number of greater than 75 (Wood, 1976). The Warren equation examines the number of interservice intervals that fall into regular and irregular periods (Gaines, 1989). Both of these methods rely on estrous cycle data acquired more than $30 \mathrm{yr}$ ago (Gwazdauskas et al., 1981; Gordon, 2011). More recently, it has become common to calculate the pregnancy risk to measure herd fertility performance. This parameter is often referred to as "21 d Preg-Rate" and evaluates the proportion of an eligible population that become pregnant within a 21-d period. If estrous cycle length has changed, these measures may give false impressions of herd performance. Additionally, although some researchers have demonstrated that interestrus intervals outside of a range of 18 to $24 \mathrm{~d}$ have a negative association with insemination success, more recent studies have contradicted this, showing improved pregnancy outcomes to insemination following longer interestrus intervals (Royal et al., 2000; Remnant et al., 2018).

Estrous cycle duration is the outcome of a complex relationship between normal physiology and pathological processes. Cows have several waves of follicle development and regression before a follicle maturing to ovulate an oocyte. The modal number of follicular waves per estrous cycle is 3 in nulliparous dairy heifers and beef cows, compared with 2 in multiparous cows although other researchers have noted a less marked trend for this (Ginther et al., 1989; Wolfenson et al., 2004). Two-wave cycles tend to give an interestrus interval $26 \mathrm{~h}$ shorter than that of a 3 -wave cycle and growth of the ovulatory follicle in animals with 2 -wave cycles lasts 2 to $3 \mathrm{~d}$ longer than in animals with 3 -wave cycles (Ahmad et al., 1997). However, the effect of these different durations on either circulating estradiol concentration or pregnancy rate are not clear, with contrasting results in different studies (Ahmad et al., 1997; Townson et al., 2002). Numerous factors influence the length of luteal and follicular phases, affecting total interestrus interval. Direct effects from ovarian pathology such as cystic ovarian follicles, persistent follicles, and persistent corpora lutea can lead to interestrus intervals out with the range of 18 to $24 \mathrm{~d}$ (Carroll et al., 1990; Taylor and Beever, 2003; Vanholder et al., 2006). Bacterial infections such as metritis, endometritis, and IMI with coliform bacteria are associated with an increased frequency of abnormal interestrus intervals (Ginther, 1968; Farin et al., 1989; Moore et al., 1991). Iatrogenic factors such as administration of bovine somatotropin or prostaglandin analogs can also affect interestrus intervals.

The objective of this study was to describe the intervals between estrus events of dairy cows from 16 herds in the United Kingdom, categorizing these as interestrus and interservice intervals and comparing these data to previously reported norms. Distinguishing between interservice and interestrus intervals will aid elucidation of the underlying mechanisms of any changes in interval. A secondary aim was to investigate any putative associations between these intervals and related fertility performance.

\section{MATERIALS AND METHODS}

\section{Farms}

Sixteen dairy herds located in the northwest of the United Kingdom were recruited based on 2 criteria. First, herd choice was based on a convenience sample of herds that the authors worked with, to allow a degree of confidence in the quality of the data through knowledge of the herds' record keeping. Second, herds employing Reproductive Management Systems (Genus Plc, Hampshire, UK) for breeding management were chosen to maximize consistency of estrus detection regimens, AI protocols, and record keeping. These herds were all of similar size (250 to 450 cows), 305-d yield (8,500 to 10,500 L), and breed (predominantly Holstein genetics). All herds had even calving patterns throughout the year.

\section{Data Collection}

The technicians involved all employed a standardized approach to estrus detection using oil-based tail chalk applied to the region of the sacrum and tail head as an aid to once daily observation. Every cow was examined for removal of chalk daily, with insemination being triggered by removal of more than $50 \%$ of the previous day's chalk. Chalk was replenished daily for each cow and repeat removal of chalk resulted in repeat insemination. Observation and insemination were conducted within the same time window each day for each herd. This resulted in a once per day insemination strategy rather than the commonly reported am-pm protocol of delaying insemination for approximately $12 \mathrm{~h}$ after initial observation of signs of estrus. All estrus events were recorded from time of calving onward, including before an animal's designated start of breeding. Events were recorded using the DairyComp 305 herd management software program (Valley Agricultural Software, Tulare, CA).

\section{Data Processing}

All data were exported to a spreadsheet program (Excel 2010, Microsoft Corp., Redmond, WA). Estrus event data (service and nonservice) were included for 
a 5-yr period (January 1, 2009, to December 31, 2013) allowing examination of data over consecutive years and comparison of individual cow data for multiple lactations. Pregnancy diagnosis records were examined for $100 \mathrm{~d}$ after the last estrus event to ensure all animals with estrus events had reasonable opportunity for pregnancy diagnosis. Detection of pregnancy was by transrectal ultrasonography carried out a minimum of $30 \mathrm{~d}$ postinsemination.

The data were filtered to identify anomalous entries, namely animals that had insemination records incompatible with the pregnancy diagnosis data or calving records, and cleaned by removal of these data points. Animals treated with exogenous hormone therapy were excluded from the date of administration for the rest of that lactation.

Interestrus intervals were defined as periods between 2 recorded estrus events of 11 to $31 \mathrm{~d}$ apart in a lactating animal with no insemination at the first estrus event. The event terminating an interestrus interval may be a service, as the act of insemination cannot exert an effect on the previous interval. Interservice intervals were defined as periods between 2 recorded estrus events of 11 to $31 \mathrm{~d}$ apart in a lactating animal with an insemination at both the first and second estrus event. Censoring intervals to those from 11 to $31 \mathrm{~d}$, inclusive, includes the greatest range of intervals possible with minimal risk of bias from estrus detection inaccuracies.

\section{Data Analysis}

Two multivariable regression models were fitted using Stata 13 (StataCorp LP, College Station, TX). Because cows are clustered within herds and interestrus and interservice intervals are clustered within cows, random effects models were fitted with random effects at both levels. Model 1 predicted parameter estimates for the interval (d) between 2 estrus events. This mixed linear model used a maximum likelihood with independent covariance structure. Model 2 was a logistic regression model using mvaghermite Gauss-Hermite quadrature to predict the odds of an insemination resulting in a pregnancy.

For both models the variable DIM was recoded in to 30-d blocks (dim30) that were then transformed as $\log _{\mathrm{e}}(\operatorname{dim} 30)$ to achieve a normal distribution. Polynomial transformations were also tested but resulted in poorer model fit. The variable parity was considered as a binary variable (primiparous vs. multiparous) based on visualization of the univariable relationships. The variable interval number (with an interval being an interestrus or interservice interval) was categorized as interval $1,2,3,4,5$, and greater than 5 to identify multiple intervals within the same lactation for the same individual cow.

Variables were considered for inclusion in initial models based on biological plausibility, with the following explanatory variables offered to the initial model 1: "days in milk" (log-transformed), "type of interval" (i.e., interestrus interval vs. interservice interval), "parity," and "interval number" (i.e., interval number within a common lactation). The following explanatory variables were offered to model 2: "interservice interval in days" (categorized in to quartiles), "days in milk" (log-transformed), "parity" (binary: primiparous vs. multiparous), and "service number" (i.e., the number of the interservice interval number within a common lactation).

A backward stepwise methodology was used to select variables for final models, taking $P<0.1$ (likelihood ratio test) to indicate improved model fit associated with retention or removal of a particular variable. Model fit for all linear models was assessed by considering the distribution of residuals and the Bayesian information criterion (Long, 1996). Model fit for logistic models was assessed using the receiver operating characteristic curve. The proportion of variance attributable to the random effect terms of farm identity and cow identity was estimated by calculating intraclass correlation coefficients from the regression models. Predicted marginal means were derived from the regression models and plotted graphically.

\section{RESULTS}

From the 16 herds examined, 6,092 cows were included in the final data set. A total of 26,980 estrus events were recorded with $24,051(89.1 \%)$ of these featuring an insemination. These service events resulted in 6,777 confirmed pregnancies, giving 0.28 pregnancies per AI (i.e., 3.55 inseminations per pregnancy). A total of 18,052 intervals were recorded, with 10,414 intervals being between 11 and $31 \mathrm{~d}$ and suitable for inclusion in analyses. These intervals were categorized as 1,747 interestrus intervals and 8,667 interservice intervals. Of these intervals, 2,953 culminated in a service that resulted in a successful pregnancy.

Figure 1 illustrates the distribution of all interestrus and interservice intervals from 1 to $100 \mathrm{~d}$. The highest frequencies of intervals occur between 18 and $28 \mathrm{~d}$ inclusive. Intervals of $1 \mathrm{~d}$ were over-represented due to the common strategy of serving cows on consecutive days. A small increase in frequency of intervals between 39 to $49 \mathrm{~d}$ was also apparent, likely corresponding to 


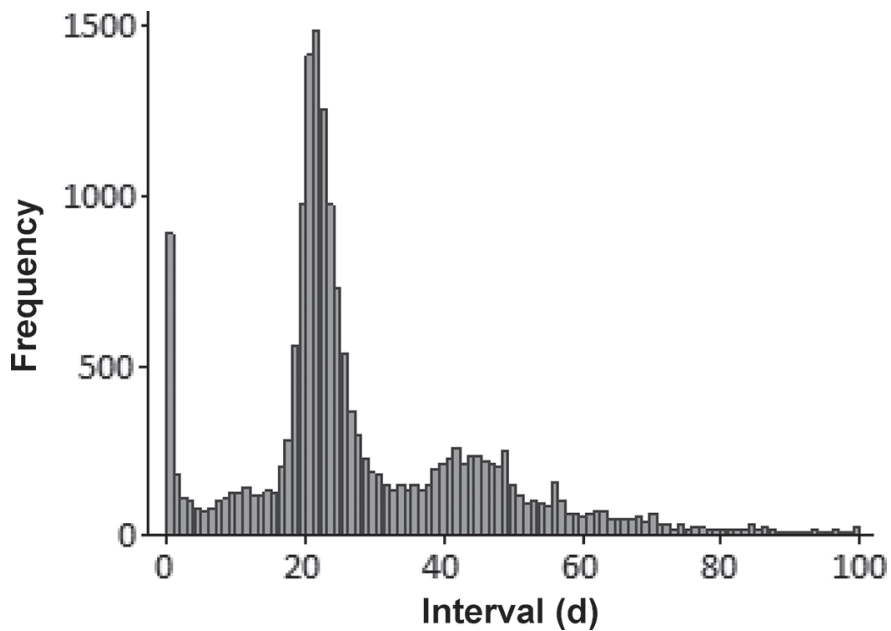

Figure 1. Distribution of intervals between all (nonservice and service) estrus events in a population of dairy cows from 16 UK herds (censored to exclude $>100$-d intervals).

observation of return to service after a single missed estrus event.

The distributions of interestrus and interservice intervals were examined by plotting histograms to allow direct comparison of these 2 subgroups (Figure 2 ). Within the censored ranges, both interestrus and interservice intervals are normally distributed around the modal values, although interestrus intervals have a small increase in the proportion of lower intervals, whereas the distribution of interservice intervals showed a slight right skew.

Based on univariable analyses, we did not observe any association between either interestrus or interservice interval and time of year of the estrus event. In addition, no association was observed between interval length and time of year of the latest calving.

\section{Model 1}

Model parameters are presented in Table 1, showing the explanatory variables that remained after backward stepwise selection. The model residuals were normally distributed, thereby demonstrating good model fit (Figure 3). Interestrus intervals were $0.45 \mathrm{~d}$ shorter (95\% CI: $0.22,0.67)$ than interservice intervals $(P<$ $0.001)$. Interval length was positively correlated with DIM, with an increase of $0.5 \mathrm{~d}$ for every $31 \mathrm{~d}$ increase in DIM $(P<0.001)$. Interval also increased with parity, as shown in Table 1 . In contrast, each increase in event number within an individual lactation resulted in a decrease in interval of $0.17 \mathrm{~d}$ (95\% CI: $-0.22,-0.13)$ after adjusting for DIM (Table 1).

The predicted effect of DIM is shown graphically for interestrus and interservice intervals (Figure 4). The predicted effect on interservice interval of the interval number within lactation after adjusting for days in milk is shown in Figure 5.

Calculation of the intraclass correlation estimates (Table 1) demonstrates that farm identity had a negligible effect on interval; however, cow identity had a major effect accounting for $9 \%$ of the residual variance after adjusting for fixed model effects.

\section{Model 2}

Model output is presented in Table 2, showing the explanatory variables that remained after backward stepwise selection. The receiver operating characteristic area of 0.85 (95\% CI: $0.839,0.855)$ confirms good model fit. This model predicts that services following different interservice intervals will have different odds of resulting in a pregnancy. Services following intervals in quartile 1 (11- to 19-d intervals) were least likely to result in a pregnancy and were regarded as the reference value.
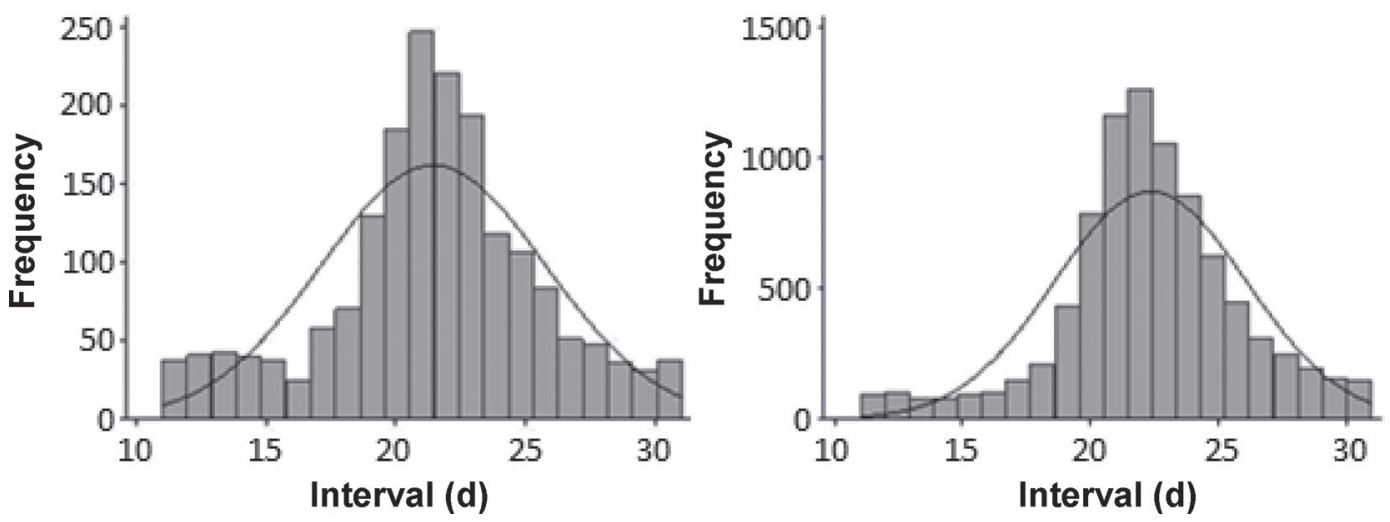

Figure 2. Distributions of interestrus intervals (left) and interservice intervals (right) censored to 11 to $31 \mathrm{~d}$ inclusive from a population of dairy cows in 16 UK herds, with black lines showing fitted normals. 
Table 1. Parameter estimates with residual intraclass correlation from a multilevel regression model predicting interestrus/interservice interval for a population of dairy cows in 16 UK herds ${ }^{1}$

\begin{tabular}{|c|c|c|c|}
\hline Outcome (interval) & Coefficient & $95 \% \mathrm{CI}$ & $P$-value \\
\hline Constant & 20.831 & $20.567,21.096$ & $<0.001$ \\
\hline \multicolumn{4}{|l|}{ Variable } \\
\hline $\log ^{\mathrm{e}}$ DIM (30-d blocks) & 1.315 & $1.069,1.561$ & $<0.001$ \\
\hline Parity 1 & Referent & & \\
\hline Parity 2 & 0.298 & $0.092,0.504$ & 0.005 \\
\hline Parity 3 & 0.374 & $0.128,0.619$ & $<0.005$ \\
\hline Parity 4 and > 4 & 0.673 & $0.448,0.898$ & $<0.001$ \\
\hline Interestrus interval & Referent & & \\
\hline Interservice interval & 0.446 & $0.218,0.674$ & $<0.001$ \\
\hline Interservice interval number & -0.304 & $-0.376,-0.232$ & $<0.001$ \\
\hline \multicolumn{4}{|l|}{ By category } \\
\hline Random effect parameter & Estimate & & \\
\hline Farm ID & 0.032 & $0.007,0.138$ & \\
\hline Cow ID & 1.327 & $1.063,1.658$ & \\
\hline Residual & 13.276 & $12.855,13.710$ & \\
\hline Random effect level & ICC & & \\
\hline Farm ID & 0.002 & $0.0001,0.009$ & \\
\hline Cow ID & 0.091 & $0.075,0.115$ & \\
\hline
\end{tabular}

${ }^{1} \mathrm{ID}=$ identification; $\mathrm{ICC}=$ intraclass correlation coefficient.

Quartile 2 services (20 to 22 d intervals) had greatest odds of resulting in pregnancy [odds ratio $(\mathbf{O R}) 1.538$, 95\% CI: $1.350,1.751]$. Quartile 3 services (following 23and 24-d intervals) were not significantly different from quartile 2 services, still having significantly higher odds of pregnancy than quartile 1 (OR 1.290, 95\% CI: 1.120 , 1.485). Services following 25 - to 31 -d intervals (quartile 4) showed a trend toward higher odds of pregnancy than quartile 1 (OR 1.174, 95\% CI: 1.023, 1.347) with a
$P$-value of 0.022 as illustrated in Figure 5. Multiparous animals were $24 \%$ less likely to become pregnant than primiparous animals (OR 0.76, 95\% CI: 0.679, 0.849) as shown in Table 2. The residual intraclass correlation estimates (Table 2) show that the effect of farm identity was small, accounting for just over $1 \%$ of all variance. Cow identity had a greater effect, accounting for almost $15 \%$ of the remaining variance after adjusting for the model fixed effects.

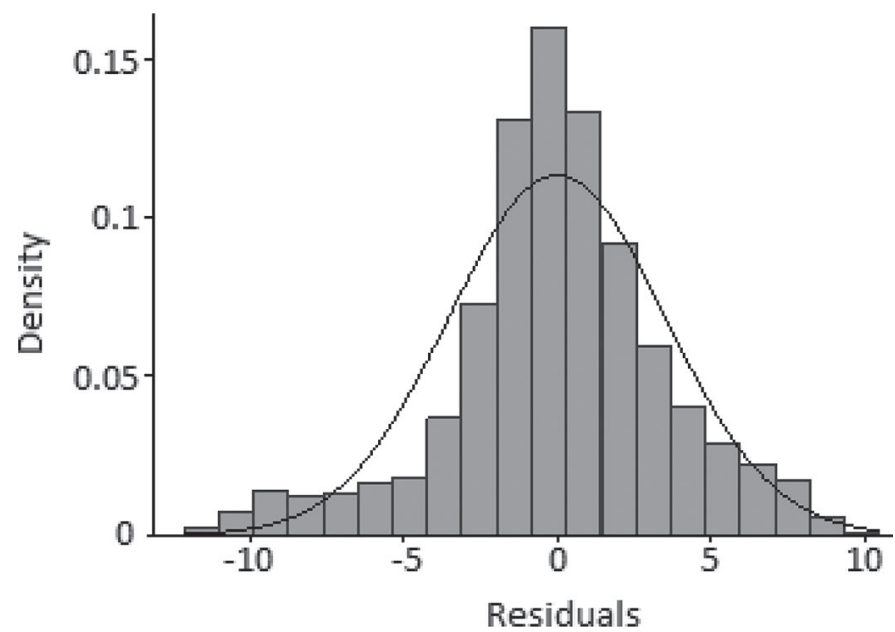

Figure 3. A histogram of the residuals for a multilevel regression model of interestrus and interservice intervals of a population of dairy cows from 16 UK herds.

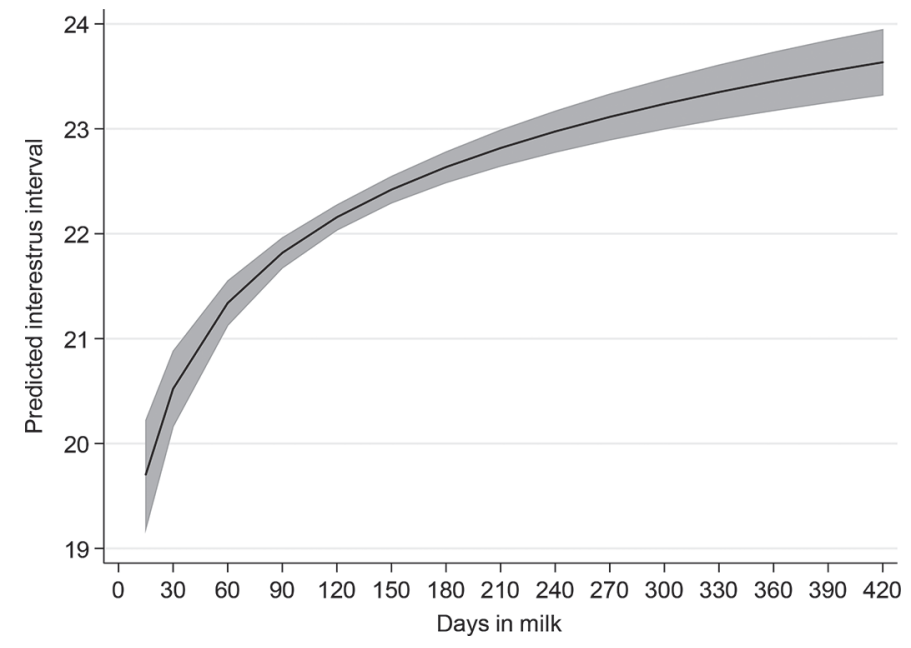

Figure 4. The predicted effect with $95 \%$ CI of DIM on all interestrus intervals in a population of dairy cows from 16 UK herds. 
Table 2. Estimates with residual intraclass correlation from a logistic regression model predicting odds ratio (OR) for achieving pregnancy in a population of dairy cows in 16 UK herds ${ }^{1}$

\begin{tabular}{lccc}
\hline Outcome & OR & $95 \%$ CI & $P$-value \\
\hline Constant & 0.442 & $0.373,0.525$ & $<0.001$ \\
Variable & & & \\
Interservice interval (d) & & & \\
Quartile 1 (11-19) & Referent & $1.350,1.751$ & $<0.001$ \\
Quartile 2 (20-22) & 1.538 & $1.120,1.485$ & $<0.001$ \\
Quartile 3 (23-24) & 1.289 & $1.023,1.347$ & $<0.022$ \\
Quartile 4 (25-31) & 1.174 & $0.684,0.857$ & \\
Primiparous & Referent & & \\
Multiparous & 0.766 & & \\
\cline { 2 - 2 } Random effect parameter & Estimate & $0.153,0.362$ & \\
\cline { 2 - 3 } Farm ID & 0.235 & $0.628,0.832$ & \\
Cow ID & 0.723 & & \\
Random effect level & ICC & $0.00611,0.0332$ & \\
Farm ID & 0.0143 & $0.118,0.187$ & \\
Cow ID & 0.149 & & \\
\hline
\end{tabular}

${ }^{1} \mathrm{ID}=$ identification; $\mathrm{ICC}=$ intraclass correlation coefficient.

\section{DISCUSSION}

This study highlights the importance of distinguishing between interestrus and interservice intervals, suggesting that the act of insemination may exert an effect on the duration of the subsequent interestrus interval. This renders interservice interval an inaccurate proxy for interestrus interval, affecting methods of evaluating estrus detection that use interservice interval data in metrics based on interestrus interval.

The modal interestrus interval was $21 \mathrm{~d}$, with intervals within the range of 11 to $31 \mathrm{~d}$ normally distributed with a left skew due to a slightly greater frequency of shorter intervals (11 to $15 \mathrm{~d}$ ) in comparison to longer

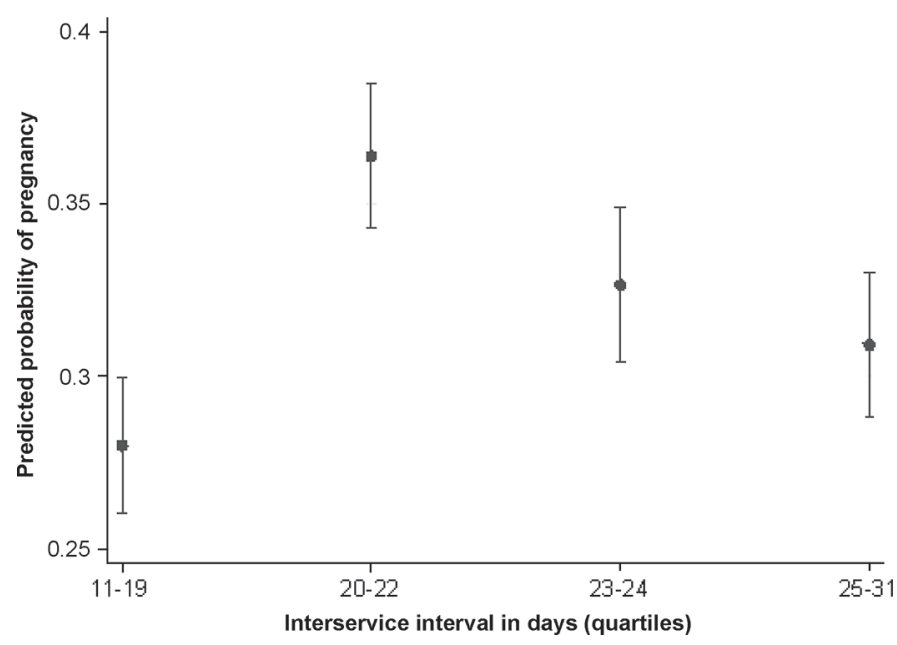

Figure 5. Predicted probability with $95 \%$ CI of pregnancy by interval length for intervals within an 11- to 31-d range. intervals $(25$ to $31 \mathrm{~d}$ ). This higher percentage of lower intervals could be due to several factors. Interestrus intervals were generally recorded at lower DIM than interservice intervals, predominantly in the first $60 \mathrm{~d}$ of lactation. This is a period of greater risk for conditions such as coliform mastitis and cystic ovarian disease, which are known risk factors for increased incidence of short interestrus intervals (Moore et al., 1991; Zulu et al., 2002; Breen et al., 2009).

Interservice intervals were longer than that commonly reported, with a modal value of $22 \mathrm{~d}$. Interservice intervals between 11 and $31 \mathrm{~d}$ were approximately normally distributed around the modal value with a slight right skew due to a higher frequency of intervals between 25 and $31 \mathrm{~d}$ than intervals in the range of 11 to 17 d. This suggests the range commonly quoted as 18 to $24 \mathrm{~d}$ (Barr, 1975) is not an appropriate description of interservice intervals, corroborating recent findings from the United Kingdom and United States (Sartori et al., 2004; Remnant et al., 2015). Previous authors have extrapolated that longer interservice intervals are likely due to an increase in time period between all estrus events, but this data set suggests that this might not be the case. Rather, it may be suggested that it is insemination that leads to the subsequent interval being longer, as opposed to an increase in interestrus interval per se.

Insemination at the first estrus event is associated with interestrus intervals that are $0.45 \mathrm{~d}$ longer after adjusting for other explanatory variables. One possible explanation of this is based on observations by Ahmad et al. (1997) that there are more 3 -wave than 2 -wave cycles during luteal periods after an insemination than 
after a nonservice estrus. Ahmad et al. (1997) reported that 3 -wave cycles are on average $26 \mathrm{~h}$ longer than 2 -wave cycles, implying that the act of insemination is likely to increase the interval to the next estrus event. However, our data set shows longer intervals in multiparous than primiparous animals. It has been demonstrated previously that, in comparison to multiparous cows, primiparous animals have a greater tendency toward 3-wave cycles than 2-wave cycles (Sartori et al., 2004). Assuming this to apply to the study population, primiparous animals would be expected to have a longer interval between estrus events than multiparous animals, which was not the case. This suggests that either these primiparous animals have a more similar follicular wave profile to multiparous animals, as described elsewhere (Wolfenson et al., 2004; Jaiswal et al., 2009), or that additional factors are affecting interestrus interval, negating the effect of wave number. Several risk factors for extended interestrus interval are more frequent in multiparous than primiparous animals. Opsomer et al. (2000) identified increasing parity as a risk factor for prolonged luteal phases. Multiparous animals have a greater incidence of hypocalcemia, twinning, and retained fetal membranes, leading to a higher risk of uterine pathology (Kinsel et al., 1998; Han and Kim, 2005; Potter et al., 2010). This has been linked to persistent luteal function and extended interestrus intervals (Taylor and Beever, 2003) possibly due to reductions in prostaglandin synthesis leading to lower luteolytic capacity (Farin et al., 1989). Extended interestrus lengths have also been attributed to late embryonic death due to subluteolytic concentrations of prostaglandin compromising embryonic development (Schrick et al., 1993; Barker et al., 1998).

Another risk factor for longer interservice intervals in multiparous animals is increasing milk yield (Remnant et al., 2015). Metabolic clearance rate of progesterone is higher in higher yielding animals (Sangsritavong et al., 2002). Reductions in plasma progesterone have been correlated with reduced luteal blood flow (Luttgenau et al., 2011), a putative cause for increased rates of late embryonic death. While metabolic clearance of progesterone is not definitively established to be lower in primiparous animals, it is possible that the rate of elimination is lower than that of multiparous cows, contributing to the disparity between their interservice intervals. This could also account for the right skew of the distribution of interservice intervals (but, importantly, not interestrus intervals), with an increase in longer intervals.

Days in milk had a strong positive association with both interestrus and interservice intervals. Model 1 predicts that this increase in interval continues beyond the usual time of peak yield, suggesting that this as- sociation is not directly related to production level. It is possible that it relates more to duration of time since the previous parturition. A constant increase in interval length throughout the lactation would suggest this effect is independent of periparturient pathologies. However, Dubuc et al. (2011) have shown metritis has a significant effect on fertility for a prolonged period during the subsequent lactation. This could alter the sample of cows as DIM increase, with subfertile animals over-represented in later lactation.

Interservice interval was negatively associated with repeat services within the same lactation. Animals with more than one interservice interval showed a reduction in duration of each subsequent interval, independent of DIM, agreeing with other recent observations (Remnant et al., 2015). The mechanisms for this are unclear.

Farm identity had a negligible effect on interval length. Cow identity accounted for $9 \%$ of total variance, which is less than expected from previous descriptions of repeatability of follicular wave patterns in individual cows (Jaiswal et al., 2009).

The interval analysis had several limitations. The data were analyzed on the assumption that all estrus events recorded between 11 and $31 \mathrm{~d}$ were true events based on accurate diagnosis. Studies using milk progesterone to assess heat detection accuracy found mean false positive diagnoses ranged from 5 to $30 \%$ (Reimers et al., 1985; Nebel et al., 1987; Sturman et al., 2000). Foote (1975) describes "nonmounting" estrus in which tail chalk will be ineffective at detecting the event, leading to false negatives extending interestrus interval. Conversely, other researchers have noted different causes of false positives due to abrasion of tail chalk or paint in social or antagonistic scenarios unrelated to estrus (Skenandore and Cardoso, 2017). False negatives are unlikely to influence the results of this study, as the extended "double" interestrus interval will be censored from the data set, but false positives may fall within the observation range of 11 to $31 \mathrm{~d}$, providing a potential source of bias. However, the data set itself conforms to expected patterns of intervals (Figure 1), suggesting that false positives are unlikely to have introduced significant bias. The fact that pregnancies per AI in this study is broadly similar to that of inseminations at estrus events confirmed by milk progesterone assay supports the supposition that the number of false positives in this study was likely to be small.

Intervals beginning with noninsemination estrus events will have a different (although overlapping) distribution by DIM to intervals started by insemination estrus events and this may only partially be corrected for in the multivariable analyses. The data set size will reduce this bias but it must be acknowledged that, without control groups of cows, these 2 subpopulations 
may not be directly comparable in physiological, environmental, or management factors.

Once per day insemination was carried out as described by Nebel et al. (1994). This protocol and the common accompanying practice of repeating insemination after $24 \mathrm{~h}$ may have influenced interservice interval by potentially reducing the preceding or subsequent interval (or both) artificially. However, correction of this would increase interservice interval lengths, exaggerating this study's findings.

Another limitation of the interval analysis was lack of data for other variables, such as disease and production factors, that are known to affect interestrus intervals. Genetic control of fertility traits has been shown to affect both ovarian activity and estrus behavior (Cummins et al., 2012) and is likely to account for the variance between cows ( $9 \%$ of total variance in model 1 ), but this information was not available for analysis in this study.

Different ranges of interservice interval were associated with different odds of conception at the second insemination of the interval. The second service of intervals from 11 to $19 \mathrm{~d}$ (quartile 1) has the lowest predicted probability of pregnancy. This is significant, given that intervals of 18 and $19 \mathrm{~d}$, previously reported as physiologically normal, are within this range. Conversely, intervals of 23 and $24 \mathrm{~d}$ (quartile 3) precede inseminations with no significant difference to the optimum odds of pregnancy. A trend was present for services following even longer intervals ( 25 to $31 \mathrm{~d}$ ) to have greater predicted probability of pregnancy than quartile 1. This corresponds with recent observations by Remnant et al. (2018) that services after intervals of 25 and $26 \mathrm{~d}$ were significantly more likely to result in pregnancy than services following intervals of 17 and 18 d. These findings suggest that some of the mechanisms underlying extended intervals might have a positive effect on fertility. This could support the hypothesis that longer intervals are due to 3 -wave cycles as some (although not all) studies have demonstrated higher pregnancy rates for 3-wave cycles (Ahmad et al., 1997; Townson et al., 2002; Bleach et al., 2004). Model 2 also showed that the effect of interservice interval on odds of pregnancy was independent of DIM.

\section{CONCLUSIONS}

Modal interestrus interval was $21 \mathrm{~d}$, conforming to established descriptions. Modal interservice interval was $22 \mathrm{~d}$. Longer interservice intervals ( 25 to $31 \mathrm{~d}$ inclusive) occur at greater frequencies than shorter intervals (11 to $17 \mathrm{~d}$ ), a pattern not seen in the distribution of interestrus intervals. This raises the possibility that insemination exerts an effect on the subsequent estrous cycle of cows that do not conceive. Intervals were also affected by parity, DIM, and number of intervals within the same lactation. Identifying mechanisms for these effects will require further investigation. Length of interservice interval was associated with the predicted probability of subsequent pregnancy. The greatest odds of pregnancy were associated with intervals of 20 to 24 d. Within the range of 11 to $31 \mathrm{~d}$, intervals greater than the median tend to increase the odds of conception to the second insemination of the interval.

\section{ACKNOWLEDGMENTS}

This work was carried out in partial fulfilment of the requirements of the Diploma of Bovine Reproduction, University of Liverpool. The data set was provided by Genus Plc, with special thanks going to Peter Jackson, Jenny Hildon, and Huw Lloyd (Genus Plc, Hampshire, UK) for their support and the provision of the data set. The work was accomplished with great support from Lambert, Leonard and May Veterinary Surgeons (Whitchurch, Shropshire, UK).

\section{REFERENCES}

Ahmad, N., E. C. Townsend, R. A. Dailey, and E. K. Inskeep. 1997. Relationships of hormonal patterns and fertility to occurrence of two or three waves of ovarian follicles, before and after breeding, in beef cows and heifers. Anim. Reprod. Sci. 49:13-28.

Barker, A. R., F. N. Schrick, M. J. Lewis, H. H. Dowlen, and S. P. Oliver. 1998. Influence of clinical mastitis on reproductive performance of Jersey cows. J. Dairy Sci. 81:1285-1290.

Barr, H. L. 1975. Influence of estrus detection on days open in dairy herds. J. Dairy Sci. 58:246-247.

Blavy, P., N. C. Friggens, K. R. Nielson, J. M. Christensen, and M. Derks. 2018. Estimating probability of insemination success using milk progesterone measurements. J. Dairy Sci. 101:1648-1660.

Bleach, E. C. L., R. G. Glencross, and P. G. Knight. 2004. Association between ovarian follicle development and pregnancy rates in dairy cows undergoing spontaneous estrous cycles. Reproduction 127:621-629.

Breen, J. E., M. J. Green, and A. J. Bradley. 2009. Quarter and cow risk factors associated with the occurrence of clinical mastitis in dairy cows in the United Kingdom. J. Dairy Sci. 92:2551-2561.

Carroll, D. J., R. A. Pierson, E. R. Hauser, R. R. Grummer, and D. K. Combs. 1990. Variability of ovarian structures and plasma progesterone profiles in dairy cows with ovarian cysts. Theriogenology 34:349-370.

Cummins, S. B., P. Lonergan, A. C. O. Evans, and S. T. Butler. 2012. Genetic merit for fertility traits in Holstein cows: II. Ovarian follicular and corpus luteum dynamics, reproductive hormones, and estrus behavior. J. Dairy Sci. 95:3698-3710.

Dubuc, J., T. F. Duffield, K. E. Leslie, J. S. Walton, and S. J. LeBlanc. 2011. Randomized clinical trial of antibiotic and prostaglandin treatments for uterine health and reproductive performance in dairy cows. J. Dairy Sci. 94:1325-1338.

Farin, P. W., L. Ball, J. D. Olson, R. G. Mortimer, R. L. Jones, W. S. Adney, and A. E. McChesney. 1989. Effect of Actinomyces pyogenes and gram-negative anaerobic bacteria on the development of bovine pyometra. Theriogenology 31:979-989.

Foote, R. H. 1975. Estrus detection and estrus detection aids. J. Dairy Sci. $58: 248-256$. 
Forde, N., M. E. Beltman, P. Lonergan, M. Diskin, J. F. Roche, and M. A. Crowe. 2011. Estrus cycles in Bos taurus cattle. Anim. Reprod. Sci. 124:163-169.

Gaines, J. D. 1989. The role of record analysis in evaluating subfertile dairy herds. Vet. Med. 84:532-543.

Ginther, O. J. 1968. Influence of exogenous progesterone and the uterus on ovarian activity in sheep. Endocrinology 83:613-615.

Ginther, O. J., L. Knopf, and J. P. Kastelic. 1989. Temporal associations among ovarian events in cattle during estrous cycles with two and three follicular waves. J. Reprod. Fertil. 87:223-230.

Gordon, P. 2011. Estrus detection in dairy cattle. In Pract. 33:542-546.

Gwazdauskas, F. C., J. A. Lineweaver, and W. E. Vinson. 1981. Rates of conception by artificial insemination of dairy cattle. J. Dairy Sci. 64:358-362.

Han, I. K., and I. H. Kim. 2005. Risk factors for retained placenta and the effect of retained placenta on the occurrence of post-partum diseases and subsequent reproductive performance in dairy cows. J. Vet. Sci. 6:53-59.

Jaiswal, R. S., J. Singh, L. Marshall, and G. P. Adams. 2009. Repeatability of two-wave and three-wave patterns of ovarian follicular development during the bovine estrous cycle. Theriogenology 72:81-90.

Kinsel, M. L., W. E. Marsh, P. L. Ruegg, and W. G. Etherington. 1998. Risk factors for twinning in dairy cows. J. Dairy Sci. 81:989-993.

Long, J. S. 1996. Regression models for categorical and limited dependent variables. Sage, Thousand Oaks, CA.

Lopez-Gatius, F. 2003. Is fertility declining in dairy cattle? A retrospective study in north eastern Spain. Theriogenology 60:89-99.

Luttgenau, J., N. Beindorff, S. E. Ulbrich, J. P. Kastelic, and H. Bollwein. 2011. Low plasma progesterone concentrations are accompanied by reduced luteal blood flow and increased size of the dominant follicle in dairy cows. Theriogenology $76: 12-22$.

Moore, D. A., J. S. Cullor, R. H. Bondurant, and W. M. Sischo. 1991 Preliminary field evidence for the association of clinical mastitis with altered interestrus intervals in dairy cattle. Theriogenology $36: 257-265$.

Nebel, R. L., W. L. Walker, M. L. McGilliard, H. Allen, and G. S. Heckman. 1994. Timing of artificial insemination of dairy cows: Fixed time once daily versus morning and afternoon. J. Dairy Sci. 77:3185-3191.

Nebel, R. L., W. D. Whittier, B. G. Casell, and J. H. Britt. 1987. Comparison of on-farm and laboratory assays for identifying errors in detection of estrus and diagnosis of pregnancy. J. Dairy Sci. 70:1471-1476.

Opsomer, G., Y. T. Grohn, J. Hertl, M. Coryn, H. Deluyker, and A de Kruif. 2000. Risk factors for post partum ovarian dysfunction in high producing dairy cows in Belgium: A field study. Theriogenology 53:841-857.

Potter, T. J., J. Guitian, J. Fishwick, P. Gordon, and M. J. Sheldon. 2010. Risk factors for clinical endometritis in postpartum dairy cattle. Theriogenology 74:127-134.

Pryce, J. E., M. D. Royal, P. C. Garnsworthy, and I. L. Mao. 2004. Fertility in the high-producing dairy cow. Livest. Prod. Sci. $86: 125-135$.
Reimers, T. J., R. D. Smith, and S. K. Newman. 1985. Management factors affecting reproductive performance of dairy cows in the North-eastern United States. J. Dairy Sci. 68:963-972.

Remnant, J. G., M. J. Green, J. N. Huxley, and C. D. Hudson. 2015. Variation in the interservice intervals of dairy cows in the United Kingdom. J. Dairy Sci. 98:889-897.

Remnant, J. G., M. J. Green, J. N. Huxley, and C. D. Hudson. 2018. Associations between dairy cow inter-service interval and probability of conception. Theriogenology 114:324-329.

Royal, M. D., A. O. Darwash, A. P. F. Flint, R. Webb, J. A. Wooliams, and G. E. Lamming. 2000. Declining fertility in dairy cattle: Changes in traditional and endocrine parameters of fertility. J. Anim. Sci. 70:487-501.

Sangsritavong, S., D. K. Combs, R. Sartori, L. E. Armetano, and M. C. Wiltbank. 2002. High feed intake increases liver blood flow and metabolism of progesterone and estradiol-17B in dairy cattle. J. Dairy Sci. 85:2831-2842.

Sartori, R., J. M. Haughian, R. D. Shaver, G. J. M. Rosa, and M. C Wiltbank. 2004. Comparison of ovarian function and circulating steroids in estrous cycles of Holstein heifers and lactating cows. J. Dairy Sci. 87:905-920.

Schrick, F. N., E. K. Inskeep, and R. L. Butcher. 1993. Pregnancy rates for embryos transferred from early postpartum beef cows in to recipients with normal estrous cycles. Biol. Reprod. 49:617-621.

Skenandore, C. S., and F. C. Cardoso. 2017. The effect of tail paint formulation and heifer behaviour on estrus detection. Int. J. Vet. Sci. Med. 5:113-120.

Sturman, H., E. A. B. Oltenacu, and R. H. Foote. 2000. Importance of inseminating only cows in estrus. Theriogenology 53:1657-1667.

Taylor, V. J., and D. E. Beever. 2003. Metabolic profiles and progesterone cycles in first lactation dairy cows. Theriogenology 59:16611677.

Townson, D. H., P. C. W. Tsang, W. R. Butler, M. Frajblat, L. C. Griel Jr., and C. J. Johnson. 2002. Relationship of fertility to ovarian follicular waves before breeding in dairy cows. J. Anim. Sci. 80:1053-1058.

Vanholder, T., G. Opsomer, and A. de Kruif. 2006. Aetiology and pathogenesis of cystic ovarian follicles in dairy cattle. Reprod. Nutr. Dev. 46:105-119.

Wolfenson, D., G. Inbar, Z. Roth, M. Kaim, A. Bloch, and R. Brawtal. 2004. Follicular dynamics and concentrations of steroids and gonadotropins in lactating cows and nulliparous heifers. Theriogenology 62:1042-1055.

Wood, P. D. P. 1976. A note on detection of estrus in cattle bred by artificial insemination and the measurement of embryonic mortality. Anim. Prod. 22:275-278.

Zulu, V. C., Y. Sawamukai, K. Nakada, K. Kida, and M. Moriyoshi. 2002. Relationship among insulin-like growth factor-1, blood metabolites and post-partum ovarian function in dairy cows. J. Vet. Med. Sci. 64:879-885. 